\title{
Improving operating room productivity and efficiency - are there any simple strategies?
}

Rising costs and diminishing reimbursements require hospitals to continually find ways to improve efficiency and productivity. The operating room (OR) is a costintensive environment requiring efficient and effective management. The power of performance of the OR is crucially dependent on the cooperation of the surgical, anaesthesia, nursing and allied health professionals involved.

Dr O'Donnell and colleagues from the Department of Anaesthesia, Cork University Hospital, Ireland studied the effects of a number of work practice changes, including modification of patient processing and additional manpower, on non-operating time, number of cases performed and patient cancellations in a dedicated soft-tissue trauma surgical unit [1]. Work practice changes included a transition from sequential patient processing to parallel patient processing and increased use of regional anaesthesia, when feasible. The study findings were disappointing because, despite additional anaesthesia input and limited work practice changes, there was no increased operating room capacity or reduction in non-operative time. A remarkable average 2 hours of operating room time was lost daily due to avoidable delays. Not unexpectedly, the expansion of regional anaesthesia use for upper extremity surgery reduced the duration of recovery room utilization and stay.

Why did the context-specific work practice changes adopted in this study design fail so spectacularly to achieve the desired primary and secondary patient outcomes? Study design and methodology limitations included an anaesthesia rather than a surgeon team

Address for correspondence: Prof. Anthony J Cunningham The Galway Clinic

Doughiska, Co. Galway, Ireland

E-mail: anthonycunningham@galwayclinic.com based-work practice model, loss of data during the baseline and study phases and failure to achieve the planned parallel rather than sequential patient processing work practice changes.

Notwithstanding the disappointing outcome of the study cited above, there are substantial opportunities to enhance OR efficiency, which depend on availability of the first case of the day, patient in room, anaesthesia ready, surgical preparation start and procedural start time. Surgeons have a particular role in standardizing tasks, collecting and using actionable data and maintaining effective team communication [2]. A single surgeon team-based work practice model reduces median change over-time and cancellation rate due to time over-runs [3]. Six Sigma is an excellent quality and performance improvement tool that has been applied in a number of medical management scenarios [4]. Multidisciplinary application of Six Sigma tools to delayed first case on-time start due to the patient, surgeon, facility and the anaesthesia department, significantly improved OR efficiency [5].

Institutions can achieve significant improvements in OR efficiency by analyzing OR data on causes of delays, devising strategies for minimizing the most common delays and subsequently measuring delay data [6]. Personal accountability, streamlining of procedures, interdisciplinary team work and accurate data collection are all important contributors to improved efficiency. OR management must ensure transparent and coordinated schedule management in the various operative specialties, goal-directed changes of the schedule with incorporation of emergencies, as well as effective organization of staff [7]. OR personnel must be kept motivated by clear management and leadership.

Lean process improvement techniques are used in industry to improve efficiency and quality while con- 
trolling costs. Process mapping identified late resident arrival in the preoperative holding as a cause of delayed first case starts [8]. Inefficiencies due to resident teaching rounds can be changed by the use of checklists, standardization, and elimination of nonvalue-added activity. While surgeon-related first case start time delays are still the most common causes, reasons for delays in studies conducted post Lean implementation are less likely to report delays due to preoperative assessment and more likely to be patient- or weatherrelated [9].

In most hospitals, patients move through their operative day in a linear fashion, starting at registration and finishing in the recovery room. Given this pattern, only one patient may occupy the efforts of the OR team at any one time. By processing patients in a parallel fashion, OR efficiency and patient throughput are improved while costs remain stable [10]. Effective scheduling, parallel processing, choice of anaesthetic techniques, and monitoring of overall OR performance are important. Performance improvement projects require attention to policies, procedures, processes, physical plant and infrastructure, personnel, and perhaps most importantly, medical politics.

\section{Conflict of interest}

Nothing to declare

Anthony J Cunningham, MD, FRCPC

Professor

Medical Director

The Galway Clinic

Doughiska, Co. Galway, Ireland

\section{References}

1. O' Donnell BD, Walsh K, Murphy A, McElroy B, Iohom G, Shorten GD: An evaluation of operating room throughput in a stand-alone soft-tissue trauma operating room. Rom J Anaesth Intensive Care 2017; 24: 13-20. doi: 10.21454/rjaic.7518. 241.wal

2. Fong AJ, Smith M, Langerman L. Efficiency improvement in the operating room. J Surg Res 2016; 204: 371-383. doi: 10.1016/j.jss.2016.04.054

3. Mizumoto R, Cristaudo AT, Hendahewa R. A surgeon-lead model to improve operating theatre change-over time and overall efficiency: A randomised controlled trial. Int J Surg 2016; 30: 83-89. doi: 10.1016/j.ijsu.2016.04.033

4. Benedetto AR. Six Sigma: not for the faint of heart. Radiol Manage 2003; 25: 40-53

5. Phieffer L, Hefner JL, Rahmanian A, Swartz J, Ellison CE, Harter R, et al. Improving Operating Room Efficiency: First Case On-Time Start Project. J Healthc Qual. 2016. doi: 10.1097/ JHQ.0000000000000018 [Epub ahead of print]

6. Overdyk FJ, Harvey SC, Fishman RL, Shippey F. Successful strategies for improving operating room efficiency at academic institutions. Anesth Analg 1998; 86: 896-906. doi: 10.1213/ 00000539-199804000-00039

7. Riedl S. Modern operating room management in the workflow of surgery. Spectrum of tasks and challenges of the future. Anaesthesist 2003; 52: 957-963. doi: 10.1007/s00101-003$0567-y$

8. Warner CJ, Walsh DB, Horvath AJ, Walsh TR, Herrick DP, Pentiss SJ, et al. Lean principles optimize on-time vascular surgery operating room starts and decrease resident work hours. J Vasc Surg 2013; 58: 1417-1422. doi: 10.1016/j.jvs.2013.05.007

9. Deldar R, Soleimani T, Harmon C, Stevens LH, Sood R, Tholpady $\mathrm{SS}$, et al. Improving first case start times using Lean in an academic medical center. Am J Surg 2017; 213: 991-995. doi: 10.1016/j.amjsurg.2016.08.025

10. Friedman DM, Sokal SM, Chang Y, Berger DL. Increasing operating room efficiency through parallel processing. Ann Surg 2006; 243: 10-14. doi: 10.1097/01.sla.0000193600.97748.b1

Rom J Anaesth Intensive Care 2017; 24 : 87-88 